\title{
DISPLACED PERSONS AND HIV CARE: CHALLENGES AND SOLUTIONS
}

\author{
Laurie Bruns, $M S$ \\ Paul Spiegel, $M D M P H$ \\ United Nations High Commissioner for Refugees
}

Countries in southern Africa host a variety of displaced populations: refugees and asylum seekers who have fled conflict or persecution in their country; internally displaced persons who are still within their country; and economic migrants moving in search of employment. Regardless of the reason for displacement, all persons have the right to the 'highest attainable standard of health', ${ }^{1}$ including HIV-related care. However, the displaced person's ability to access care can be fraught with challenges. They often do not speak the language in the area to which they have moved. They might not be familiar with local systems or services. They may have knowledge gaps, particularly related to HIV and AIDS, and have specific support needs owing to lack of traditional community and family support structures. But one of the greatest barriers to access to care is one that can easily be surmounted: reluctance on the part of health professionals, from nurses to clinicians, to make the extra effort necessary to deliver services to such individuals.

The reasons for this reluctance are varied. Certain myths about displaced persons persist, such as the belief that they are more likely to engage in high-risk behaviour, or that they are too mobile to adhere to antiretroviral therapy (ART) and therefore pose a risk of developing resistance. None of the available evidence supports these perceptions; on the contrary, the evidence we have for refugee populations, for example, demonstrates fewer risky behaviours in comparison with the host community. ${ }^{2,3}$ However, every situation is context-specific and must be evaluated as such.

By the end of 2003, refugee populations remained in their host country for an average of 17 years. ${ }^{4}$ Furthermore, behavioural surveillance surveys show a high level of interaction between refugee and host communities; clearly the exclusion of displaced persons from local HIV and AIDS-related services is detrimental to efforts in HIV prevention, care and treatment to both displaced persons and the surrounding host communities. $^{5}$

According to the World Health Organization (WHO), the largest threat for developing resistance to ART is persons taking their medications in an incorrect manner; ${ }_{i}^{6}$ this threat is no larger for displaced populations than for other populations.

Differing treatment regimens and treatment interruption between area of origin and area of displacement may also pose a challenge to clinicians. However, clear guidance on this issue has been developed through a consultative process led by the

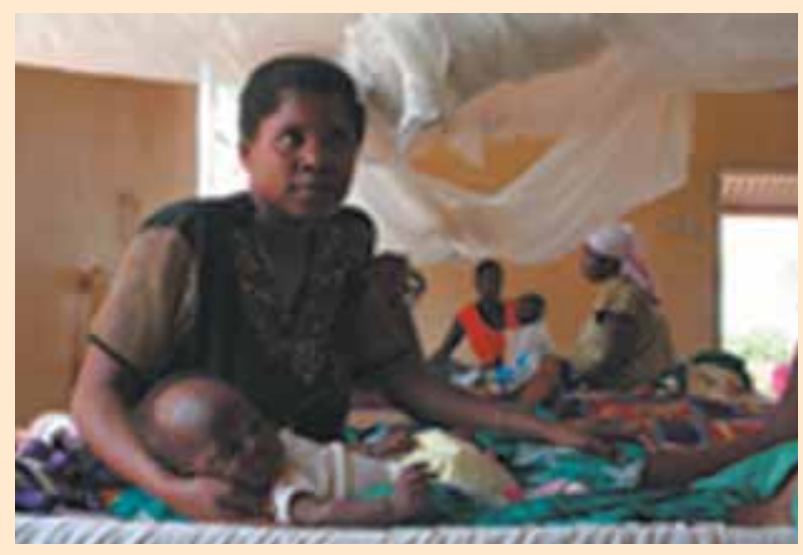

Clinic in Zambia serving refugees and locals, 2006 (J Redden, UNHCR).

Southern African HIV Clinicians Society and UNHCR (included in this issue of the journal).

Lack of awareness of the rights of displaced persons, together with xenophobia, can lead health professionals to deny care. In a survey conducted among urban refugees in South Africa in $2003,{ }^{7} 30 \%$ of respondents who had been denied emergency medical care, which is guaranteed to everyone under the national Constitution, reported that the denial came directly from a doctor or a nurse. The reasons given varied, but many practitioners showed a lack of familiarity with refugee rights, as well as a belief that such services were 'only provided to South Africans.

In fact, the HIV care needs of displaced persons are, for the most part, not different to those of local patients; a bit of empathy and creativity will go a long way towards finding ways of providing the same quality of services to these populations. In a number of countries in the southern African region, creative approaches to some of these challenges have already been employed. In Botswana and South Africa, local non-governmental organisations (NGOs) maintain a roster of trained interpreters to help with communication and adherence support. In Mozambique and Namibia, UNHCR and its NGO partners provide support for transport from refugee camps to the nearest ART site. UNHCR has also produced or translated existing HIV information materials into local refugee and migrant languages. These materials are a very effective means of educating patients, whether dealing with prevention, care or treatment. The only problem was language, which again, with a bit of initiative, has been quite easily overcome. 


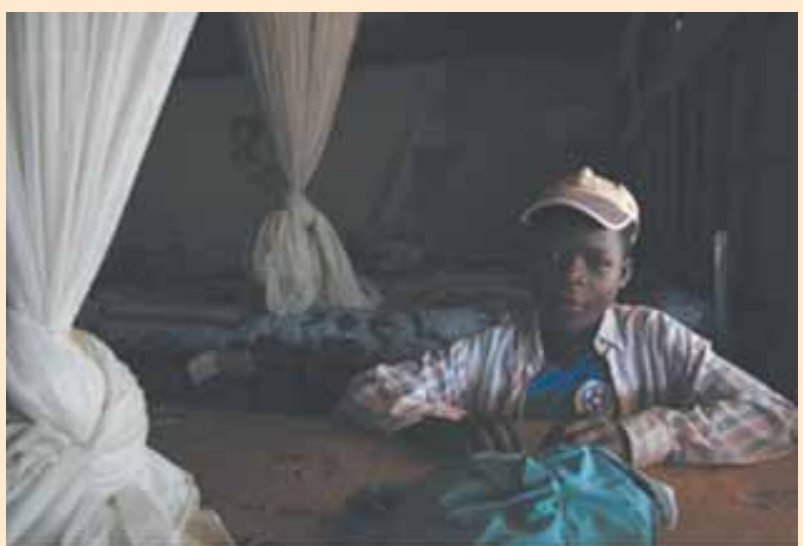

Displaced boy, Luena, Angola, 2006 (J Redden, UNHCR).

WHO, together with UNHCR, UNICEF and other international organisations, recently held an expert consultation on delivering antiretrovirals in emergencies. In the consensus statement from this meeting, they conclude:

'That emergencies ... should not affect one's access to HIV services and that the provision of such services is not only feasible, but an inalienable human right and a public health necessity. ${ }^{18}$

HIV knows no borders, nor individuals. Addressing the HIVrelated needs of displaced persons in an equitable, nondiscriminatory manner is a critical intervention in the fight against HIV and AIDS, particularly in sub-Saharan Africa.

\section{REFERENCES}

1. International Convenant on Economic, Social and Cultural Rights (ICESCR).

2. UNHCR. HIV and AIDS Behavioural Surveillance Survey, Marratane Refugee Camp, Mozambique. November 2005.

3. Spiegel, PB. HIVIAIDS among conflict-affected and displaced populations: dispelling myths and taking action. Disasters 2004; 28(3): 322-339.

4. UNAIDS, UNHCR. Strategies to Support the HIV-related Needs of Refugees and Host Populations. Geneva: UNAIDS Best Practice Collection, 2005.

5. UNHCR. Antiretroviral Medication Policy for Refugees. Geneva, January 2007.

6. WHO. HIV drug resistance. Geneva, 2006. http://www.who.int/hiv/drug resistance/en/

7. Japan International Cooperation Agency (JICA) \& UNHCR. National Refugee Baseline Survey: Final Report. November 2003.

8. WHO, UNAIDS, UNHCR, UNICEF, Medecins sans Frontieres, et al. Consensus statement: Delivering Antiretroviral Drugs in Emergencies: Neglected but Feasible. 2006 